\title{
SIADH: A RARE ENTITY IN HEAD AND NECK CANCER- A CASE REPORT WITH REVIEW OF LITERATURE
}

\section{Rinsha Gireesh*}

\section{Kaustubh Bendale}

Resident, Department of Oral and Maxillofacial Surgery, College Of Dental College Sciences, Rajiv Gandhi University of Health Sciences, Davangere, Karnataka. *Corresponding Author

Resident, Department of Oral and Maxillofacial Surgery, College Of Dental College Sciences, Rajiv Gandhi University of Health Sciences, Davangere, Karnataka.

Professor, Department of Oral and Maxillofacial Surgery, College Of Dental College Sciences, Rajiv Gandhi University of Health Sciences, Davangere, Karnataka.

\section{Shiva Bharani}

Professor \& Head, Department of Oral and Maxillofacial Surgery, College Of Dental College Sciences, Rajiv Gandhi University of Health Sciences, Davangere, Karnataka.

ABSTRACT Hyponatremia secondary to malignancy is a rare finding. Syndrome of inappropriate ADH secretion in head and neck cancer patient can be a serious comorbidity leading to decline in the survival rate. However, most of the time it goes undetected at the outset. And the pathophysiology of this link is not clarified. This article highlights a case of SIADH developed in 40-yr-old man with oral cancer. Also, focusses on the importance of diagnosing it and rendering treatment at the earliest.

\section{KEYWORDS : hyponatremia, ADH, squamous cell carcinoma, SIADH, metabolic disorder}

\section{INTRODUCTION}

Syndrome of inappropriate antidiuretic hormone secretion is the disease characterized by loss of sodium through urine due to hypersecretion of antidiuretic hormone. The occurrence of this is often reported as a systemic response to cancer defined by a serum sodium level $<135 \mathrm{mEq} / \mathrm{L}^{1}$. Around 67\% cases reported in the literature are related to small cell carcinoma of the lung ${ }^{2}$. Decrease in plasma sodium concentration being a common finding in hospitalized patients, hyponatremia is not given much clinical significance ${ }^{3}$. The euvolemic state of extracellular fluid has to be ascertained before confirming SIADH as it remains a diagnosis of exclusion. However, it goes undetected in the early phase due to the physiological compensation. Here, we report a case of oral cancer found to have SIADH.

\section{Case Report}

A 40-year old male patient sorted the out-patient department on 19th august 2016 with two months history of painful growth over left inner cheek region and weight loss since 6 months. He also had a history of chronic tobacco chewing and alcohol consumption. He did not have any significant medical history. Further, eliciting the details and evaluating the patient, imaging and routine laboratory investigations were done. Electrolyte panel showed mild decrease in the value of sodium, not very significant. Followed by this, biopsy was performed which revealed well differentiated squamous cell carcinoma of left buccal mucosa and gingivobuccal sulcus. Patient underwent surgery for the same on $22^{\text {nd }}$ September 2016. And, the Immediate post-operative days were uneventful.

As per the protocol followed by the unit, a complete hemogram and electrolytes were repeated on $5^{\text {th }}$ post-operative day, which showed serum sodium level of $123.4 \mathrm{mmol} / \mathrm{L}$ without any symptoms of hyponatremia. Based on this, a repeat investigation was done for confirmation, which again revealed a decreased level.

Considering the hyponatremia, sodium correction was performed in accordance with the protocol. Subsequent investigation did not show any improvement. On $10^{\text {th }}$ postoperative day patient developed delirium with a GCS score of E3V3M5. Following this renal, liver and thyroid function test were done to rule out the causes of pseudo hyponatremia and all were within normal limits. Few more laboratory investigations were done with the results including a serum sodium $120 \mathrm{mmol} / \mathrm{L}$ and serum osmolality $256 \mathrm{mOsm} / \mathrm{kg}$. The urinary osmolality was $324 \mathrm{mOsm} / \mathrm{kg}$ and urinary sodium 122 $\mathrm{mmol} / \mathrm{L}$. Also, plasma AVP levels were inappropriately elevated relative to plasma Osmolality.

After differentiating from the other causes of hyponatremia SIADH was diagnosed based on the relevant findings. The patient was treated with $3 \%$ hypertonic saline infusion, oral salt supplement and fluid restriction. By $14^{\text {th }}$ post-operative day symptoms subsided and the values were normalized. The GCS score improved to E4V5M6.

The etiology of SIADH here could be ectopic production of ADH by tumour itself. The symptoms subsided within few days of treatment, electrolyte values were normalized and the patient recovered.

\section{DISCUSSION}

Alexander Leaf and Audley R. Mamby initially described SIADH in the year of $1951^{4}$. Later, Schwartz in 1957 was the first to suggest that small cell carcinoma produced some quantity of antidiuretic hormone ${ }^{2}$. He described hyponatremia associated with urinary sodium loss in two patients with lung cancer ${ }^{5}$. Hypothesis proposed by Schwartz was proven by detecting ectopic AVP in small cell carcinoma of the lung with inappropriate diuresis ${ }^{6}$. Early identification of the cause and precise treatment is required for normalization of the same.

The incidence of SIADH is about $3 \%$ in head and neck cancer ${ }^{7,8}$. It was Moses et al. in 1976 who first described SIADH in patients with squamous cell carcinoma ${ }^{9}$. Head and neck malignancy linked with SIADH is mostly found in oral cavity although various other sites are reported ${ }^{10}$.

In 1987 Tadashi okotumo et al reported a case of SIADH 
caused by ectopic production of arginine vasopressin (AVP) by squamous cell carcinoma of tongue and floor of mouth ${ }^{11}$. Zohar et al in 1991 described four patients with advanced cancer of the head and neck region with coexisting SIADH ${ }^{12}$. Similarly, in 2005 Danielides et al reported a case secondary to recurrent oral cancer ${ }^{13}$.

Most of the patients remain asymptomatic initially followed by symptoms like nausea, tremors, depression, hallucination and lethargy to severe neurological manifestations ${ }^{7}$. The earliest findings noted are nausea and malaise when the plasma sodium concentration falls below $125 \mathrm{mEq} / \mathrm{L}$ to 130 $\mathrm{mEq} / \mathrm{L}$. And severe neurological manifestations are seen when it falls abruptly below $115 \mathrm{mEq} / \mathrm{L}$ to $120 \mathrm{mEq} / \mathrm{L}{ }^{14}$. The symptoms may precede or accompany diagnosis or intervention for the tumor and may be detected only in few patients ${ }^{15}$.

It is also important to exclude adrenal insufficiency and hypothyroidism before concluding SIADH secondary to malignancy. As former elevates plasma $\mathrm{ADH}$ and latter causes impaired diluting ability ${ }^{16,17}$.

The main determinant of plasma osmolality is the sodium concentration. When plasma osmolality decreases, water shift from the extracellular to the intracellular fluid compartment leading to hyponatremia. The neurologic symptoms that may be associated with hyponatremia is further due to overhydration of brain cells ${ }^{18}$. Although the serum sodium levels decrease progressively, due to the brain's adaptive mechanisms symptoms doesn't appear in the early phase. Further failure of adaptation leads to the appearance of mild to severe neurological symptoms ${ }^{19}$. The key to effective management is timely diagnosis and strategic treatment planning.

Schwartz and Bartter in 1967 defined diagnostic criteria for SIADH which excludes other systemic causes. (Table 1$)^{5}$.

\begin{tabular}{|ll|}
\hline Schwartz and Bartter Criteria \\
\hline$\cdot$ & Serum sodium $<135 \mathrm{mEq} / \mathrm{L}$ \\
\hline$\cdot$ & Serum osmolality $<275 \mathrm{mOsm} / \mathrm{kg}$ \\
\hline$\cdot$ & Urine sodium $>40 \mathrm{mEq} / \mathrm{L}$ \\
\hline$\cdot$ & Urine osmolality $>100 \mathrm{mOsm} / \mathrm{kg}$ \\
\hline$\cdot$ & Absence of clinical evidence of volume depletion \\
\hline$\cdot$ & Correction of hyponatremia by fluid restriction \\
\hline Additional Criteria \\
\hline- & Serum uric acid $<4 \mathrm{mg} / \mathrm{dl}$ \\
\hline- & Worsening of hyponatremia with IV normal saline infusion \\
\hline$\cdot$ & Plasma vasopressin elevated relative to serum osmolality \\
\hline- & Abnormal response to water load test \\
\hline
\end{tabular}

After establishing the diagnosis, adopting the right treatment protocol matters for the faster resolution of the condition. According to Moses et al. fluid restriction to about $800-1000 \mathrm{ml}$ daily is required to treat mild to moderate symptoms. It can lead to steady increase in serum sodium or osmolality ${ }^{9}$. Similarly, according to Onitilo et al fluid restriction around $500 \mathrm{ml} /$ day to $1000 \mathrm{ml} /$ day may be useful for treating mild asymptomatic hyponatremia ${ }^{20}$. And severe cases should be treated with $3 \%$ hypertonic saline to increase free water excretion under close monitoring.

Rapid correction in asymptomatic patients may lead to a fatal neurological condition called osmotic demyelination syndrome which may be due to sudden loss of tonicity of neural cells. Therefore, in asymptomatic patients, sodium correction should not be done more than $8 \mathrm{mmol} / \mathrm{L} / 24$ hours whereas in symptomatic patients, not more than $10 \mathrm{mmol} / \mathrm{L} / 24$ hours to 12 $\mathrm{mmol} / \mathrm{L} / 24$ hours ${ }^{21}$. The case we described here was treated with fluid restriction to $1000 \mathrm{ml} /$ day and hypertonic saline infusion for sodium correction with very close monitoring of serum sodium levels in the initial 24-48 hours. Symptoms resolved within few days of initiation of the treatment.

Negative fluid balance leading to the normalized serum sodium level by method of fluid restriction is the mainstay of the treatment. Presently, there are drugs antagonizing the vasopressin type 2 receptor in the distal tubule aiming highly effective treatment, advantage being correction without any discomfort of fluid restriction ${ }^{22}$. But, according to literature focus should be majorly on treating the etiology, that is the malignancy itself. The algorithm we adopted included removal of the cause along with systematic treatment in accordance with the criterion.

\section{CONCLUSION}

Detailed clinical history with adequate laboratory investigations direct towards accurate diagnosis which is critical to ensure appropriate therapy. The studies conducted so far proves SIADH can have deleterious effect in patients with malignancy especially in terms of survival as it is a serious comorbidity. Early identification and treatment of the underlying etiology is crucial to eliminate the root cause of SIADH. However, it is also important to have additional studies enlightening the pathophysiology of SIADH secondary to malignancy.

\section{Abbreviations:}

SIADH : Syndrome Of Inappropriate Antidiuretic Hormone Secretion, GCS: Glasgow Coma Scale, ADH: Antudiuretic Hormone

\section{REFERENCES}

1) Palmer BF, Gates JR, Lader M. Causes and management of hyponatremia. Annals of Pharmacotherapy. 2003 Nov;37(11):1694-702

2) Yoo, Minwook, Evelyn Oteng Bediako, and Ozan Akca. "Syndrome of inappropriate antidiuretic hormone (SIADH) secretion caused by squamous cell carcinoma of the nasopharynx: case report." Clinical and experimental otorhinolaryngology 1.2 (2008): 110.

3) Anderson RJ, Chung HM, Kluge R, Schrier RW. Hyponatremia: a prospective analysis of its epidemiology and the pathogenetic role of vasopressin. Annals of internal medicine. $1985 \mathrm{Feb} 1 ; 102(2): 164-8$

4) Pillai, Binu P., Ambika Gopalakrishnan Unnikrishnan, and Praveen V. Pavithran. "Syndrome of inappropriate antidiuretic hormone secretion Revisiting a classical endocrine disorder." Indian journal of endocrinology and metabolism 15.Suppl3 (2011): S208.

5) Schwartz WB, Bennet TW, Curelop S, Bartter FC: A syndrome of renal sodium loss and hyponatremia probably resulting from inappropriate secretion of antidiuretic hormone. Am J Med23:529-542,1957

6) Amatruda Jr TT, Mulrow PJ, Gallagher JC, Sawyer WH. Carcinoma of the lung with inappropriate antidiuresis: Demonstration of antidiuretic-hormone-like activity in tumor extract. New England Journal of Medicine. 1963 Sep 12;269(11):544-9.

7) Thompson M, Adlam DM. Syndrome of inappropriate antidiuretic hormone secretion associated with oral squamous cell carcinoma. British Journal of Oral and Maxillofacial Surgery. 2002 Jun 1;40(3):216-9.

8) Sorensen JB, Andersen MK, Hansen HH. Syndrome of inappropriate secretion of antidiuretic hormone (SIADH) in malignant disease. Journal of internal medicine. 1995 Aug:238(2):97-110.

9) Moses AM, Miller M, Streeten DH. Pathophysiologic and pharmacologic alterations in the release and action of ADH. Metabolism. 1976 Jun $1 ; 25(6): 697-721$

10) Ferlito A, Rinaldo A, Devaney KO. Syndrome of inappropriate antidiuretic hormone secretion associated with head and neck cancers: review of the literature. Annals of Otology, Rhinology \& Laryngology. 1997 Oct; 106(10):878-83.

11) Okutomi T, Sakata S, Tatematsu N, Oka N. Squamous cell carcinoma of tongue and floor of mouth associated with syndrome of inappropriate secretion of antidiuretic hormone. Journal of oral and maxillofacial surgery. 1987 May 1;45(5):447-9.

12) Zohar, Yuval, et al. "Syndrome of inappropriate antidiuretic hormone secretion in cancer of the head and neck." Annals of Otology, Rhinology \& Laryngology 100.4 (1991): 341-344

13) Danielides $V^{1}$, Milionis HJ, Karavasilis V, Briasoulis E, Elisaf MS. Syndrome of inappropriate antidiuretic hormone secretion due to recurrent oral cancer.BENT. 2005:1(3):151-3.PMID: 16255500

14) Ellis SJ. Severe hyponatraemia: complications and treatment. QJM: An International Journal of Medicine. 1995 Dec 1;88(12):905-9.

15) List AF, Hainsworth JD, Davis BW, Hande KR, Greco FA, Johnson DH. The syndrome of inappropriate secretion of antidiuretic hormone (SIADH) in small-cell lung cancer. Journal of Clinical Oncology. 1986 Aug;4(8):1191-8.

16) Bartter FC, Schwartz WB. The syndrome of inappropriate secretion of antidiuretic hormone. The American journal of medicine. 1967 May 1;42(5):790-806

17) Derubertis FR, Michelis MF, Bloom ME, Mintz DH, Field JB, Davis BB. Impaired water excretion in myxedema. The American journal of medicine. $1971 \mathrm{Jul}$ $1 ; 51(1): 41-53$

18) Decaux G, Musch W. Clinical laboratory evaluation of the syndrome of inappropriate secretion of antidiuretic hormone. Clinical Journal of the American Society of Nephrology. 2008 Jul 1;3(4):1175-84. 
19) Castillo JJ, Vincent M, Justice E. Diagnosis and management of hyponatremia in cancer patients. The oncologist. 2012 Jun; 17(6):756.

20) Onitilo AA, Kio E, Doi SA. Tumor-related hyponatremia. Clinical medicine \& research. 2007 Dec 1;5(4):228-37.

21) Adrogué HJ, Madias NEN Hyponatremia Engl J Med. 2000 May 25; 342(21):1581-9.

22) Verbalis JG, Adler S, Schrier RW, Berl T, Zhao Q, Czerwiec FS. Efficacy and safety of oral tolvaptan therapy in patients with the syndrome of inappropriate antidiuretic hormone secretion. European journal of endocrinology. 2011 May $1 ; 164(5): 725-32$. 